\title{
Internal surface area and other measurements in emphysema
}

\author{
W I L L I A M M . T H U R L B E C K \\ From the Department of Pathology, Pathological Institute-McGill University, Montreal 2, Quebec, Canada
}

\begin{abstract}
Some measurements of emphysema were made on 29 pairs of non-emphysematous lungs and 44 pairs of emphysematous lungs inflated at a standard transpulmonary pressure of $25 \mathrm{~cm}$. of formalin. These were: a subjective visual assessment (units); an assessment of the volume of the lung parenchyma involved by emphysema (point count); an average subjective visual grading by eight pathologists (Co-op score); mean linear intercept or average distance between alveolar walls at a transpulmonary pressure of $25 \mathrm{~cm}$. of formalin $(\mathrm{Lm})$; mean linear intercept corrected to total lung capacity ( $\left(\mathrm{m}_{\mathrm{c}}\right)$; internal (alveolar) surface area at $25 \mathrm{~cm}$. transpulmonary pressure (ISA) ; internal surface area at total lung capacity (ISA C $_{C}$; internal surface area corrected to an arbitrary lung volume of 5 litres (ISA $)_{5}$. Internal surface area measurements were generally decreased in severe emphysema. Because of the wide range of ISA and ISA $A_{c}$ in non-emphysematous lungs, most emphysematous lungs fell within the normal range. The range of ISA was smaller in non-emphysematous lungs and most emphysematous lungs fell outside this range. ISA $_{5}$ in 'mild' emphysema was not distinguishable from non-emphysematous lungs. Most emphysematous lungs in which the surface area was decreased less than expected from subjective assessment were examples of centrilobular emphysema. $\mathrm{Lm}$ and $\mathrm{Lm}_{\mathrm{C}}$ were increased in emphysema. ISA $A_{5}, \mathrm{Lm}$, and $\mathrm{Lm}_{\mathrm{C}}$ paralleled the subjective assessments of emphysema rather better than ISA or ISA $A_{c}$, even when the latter were expressed as a percentage of predicted. Lm and $\mathrm{Lm}_{\mathrm{C}}$ in lungs with mild emphysema fell within the ranges found in non-emphysematous lungs, but the mean value of $\mathrm{Lm}$ in lungs with 'mild' emphysema was different from the mean $\mathrm{Lm}$ of non-emphysematous lungs, at conventional levels of significance. Since objective methods did not recognize adequately examples of 'mild' emphysema, a subjective visual grading system (with its limitations) may have a definite place.
\end{abstract}

While physiologists and clinicians have measured normal and abnormal function of the lung for years, it is only recently that anatomists and pathologists have made extensive measurements of pulmonary structure. These measurements have been pioneered by Weibel (1963) in the normal lung and by Duguid, Hulse, Richardson, and Young (1953), Duguid, Young, Cauna, and Lambert (1964), and Dunnill $(1962 \mathrm{a}, 1964,1965)$ in the abnormal lung. Since emphysema is generally defined as a process of enlargement and destruction of the bronchial tree distal to the terminal bronchiole (the alveolated portion of the lung), it seemed of value to assess the loss of internal (alveolar) surface area in a large group of patients with varying amounts of emphysema, particularly since relatively few measurements have been published thus far. It is also clear that subjective assessments of emphysema may vary from one observer to the next (Stuart-Harris, 1965), and it appeared possible that internal surface area might be a useful measurement of pulmonary emphysema. This paper assesses the loss of internal surface area which occurs in emphysema and attempts to evaluate some possible objective methods of measuring emphysema.

\section{MATERIALS AND METHODS}

The material consisted of 29 pairs of non-emphysematous lungs and 44 pairs of emphysematous lungs. ${ }^{1}$ Twenty-five pairs of the non-emphysematous lungs were as free from disease as possible and they have been described elsewhere (Thurlbeck, 1967a). All were considered free from emphysema and were also free from acute and chronic lung disease such as pneumonia, tumour, etc. Moderate acute congestion and focal oedema was present in some. The remaining four pairs of non-emphysematous lungs came from patients who had ante-mortem tests of pulmonary

1Only one lung was available in five of the patients, three with emphysema, two without. In these patients the left lung was assumed to provide $47 \%$ of the surface area. 
function; two of these had terminal acute congestion and pneumonia, and one had extensive intrapulmonary haemorrhage. The emphysematous lungs came from patients who had ante-mortem tests of pulmonary function. Many of these patients had a terminal pneumonia but none had chronic heart disease or lung disease other than emphysema, asthma, or bronchitis, thought likely to interfere with pulmonary function.

All lungs were inflated intrabronchially with $10 \%$ formalin at a constant transpulmonary pressure of $25 \mathrm{~cm}$. of formalin for at least 18 hours. The lung volumes were determined by water displacement at the end of the period of inflation and this lung volume will be termed the total lung volume (TLV). The lungs were sliced sagittally at $1-\mathrm{cm}$. intervals and impregnated with barium sulphate (Heard, 1958). The slices were then floated under water and examined with a dissecting microscope. Those thought free from emphysema at this examination constituted the nonemphysematous lungs. The emphysematous lungs were assessed and graded in each of 10 zones as 'mild', 'moderate', or 'severe', using standard grading pictures (Thurlbeck, 1963a) derived from a Ciba Guest Symposium (1959). Numerical values were given to these grades, 'mild' being given the value 1 , 'moderate' the value 2 , and 'severe' the value 3 . These assessments were then summed, the result being expressed out of a maximum of thirty. Typical, unusual, or doubtful regions were photographed and corresponding regions were taken at the time of this examination for subsequent histological study.

A simple modification of Dunnill's (1962a) technique was used to assess the extent of involvement of emphysema. A rigid plastic sheet was placed over the lung slices. Holes, $1 \cdot 1 \mathrm{~mm}$. in diameter and $1 \mathrm{~cm}$. equidistant from each other, had been drilled through the sheet, and the sheet and lung slices were then examined under water. The tissue underlying each hole was categorized, using a dissecting microscope, as either non-parenchyma (tissue more than $1 \cdot 1 \mathrm{~mm}$. in diameter), parenchyma (normal tissue less than $1 \cdot 1$ mm. in diameter), or emphysema, classified by type. The dominant tissue was scored, i.e., if more than one type of tissue lay beneath a hole, then the type of tissue which occupied the greater portion of the hole was recorded. Non-parenchyma was excluded and emphysema was expressed as a percentage of lung parenchyma, i.e.,

$$
\% \text { emphysema }=\frac{\text { emphysema }}{\text { emphysema }+ \text { parenchyma }} \times 100
$$

Each cut through the lung produces two contiguous, mirror-image surfaces. Only one of these surfaces was counted, starting with the lateral surface of the most medial cut and alternating to medial then lateral of the other contiguous surfaces. This assessment of emphysema will be referred to as the 'point count' assessment, and is abbreviated as ' $\% E$ ' in the legends to the figures.

The mid-sagittal slice of lung was submitted for a paper-mounted whole-lung section, using the Gough-
Wentworth technique. Stratified random blocks were taken from the remaining slices and these were used for making the following measurements, which will also be referred to as 'objective measurements':

Lm mean linear intercept (average distance between alveolar walls) in parenchyma, as defined above, at a transpulmonary pressure of $25 \mathrm{~cm}$. of formalin ;

Lm $\mathrm{m}_{\mathrm{C}}$ mean linear intercept corrected to measured TLC in patients with ante-mortem tests of pulmonary function or corrected to predicted TLC in non-emphysematous patients without ante-mortem tests of pulmonary function ;

ISA alveolar surface area at $25 \mathrm{~cm}$. of formalin distending pressure ;

ISAc alveolar surface area corrected to measured or predicted TLC ;

ISA $_{5}$ alveolar surface area corrected to an arbitrary lung volume of 5 litres.

In addition, the above could all be expressed as a percentage of predicted (Thurlbeck, 1967a) and will be designated by adding a per cent sign after the symbol.

The methods used to obtain these measurements were very similar to those of Dunnill (1962a, 1964) and Weibel (1963) and have been described in detail elsewhere (Thurlbeck, 1967a). Measurements were made on processed tissue, but Lm and ISA refer to measurements on fresh tissue by correcting for tissue shrinkage. The assumption made in correcting to $\mathrm{Lm}_{\mathrm{C}}$, ISAc, and ISAs is that the lung changes equally in all dimensions, i.e., linear dimensions change with the cube root of the change of volume, and twodimensional changes (area) change to the two-thirds power of the change of lung volume. The arbitrary lung volume was chosen because there was no way of being certain of accurately reproducing lung volumes as they existed during life (Thurlbeck, 1967b).

Internal surface area measurements in emphysematous lungs were made from two sets of five random blocks of tissue from all available slices of each lung, excluding the mid-sagittal slices, rather than on one set of five blocks from the lateral slices as had been used in non-emphysematous lungs. This was done because, in general, the standard error of the mean linear intercept from only five blocks was often high $(>2.5 \%)$ in emphysematous patients, particularly when emphysema was severe.

When all material had been processed (the gross assessment of emphysema, photographs, whole-lung sections, specific and random section) a final subjective score to a maximum of 30 units was given to the lung based on all these data. When there was a discrepancy between the two lungs, the scores of the lungs were averaged. These scores were made before the various objective measurements had been made and will be referred to as the 'unit score' or as 'units'.

Whole-lung sections from 22 lungs were circulated to eight pathologists expert in the pathology of emphysema as part of a separate project. They were asked to assess the amount of emphysema in the lung, 
using whatever criteria they currently used. All the pathologists filled in a check sheet in which emphysema was categorized as being absent, mild, moderate, or severe. These were given the values of $0,1,2$, or 3 respectively. The scores given to each lung by the observers were summed and then averaged, and this value will be referred to as the 'Co-op score'.

\section{RESULTS}

A table which gives all the data on all the lungs is on file with the editorial office of Thorax, and copies may be obtained from the author.

Table I shows the relationship between the subjective assessment of emphysema (units, Co-op score, and the point count) and the parameters on all lungs, whether emphysematous or not. The relationships are expressed as correlation coefficients. ${ }^{1}$ Table II shows the same relationships but for emphysematous lungs only. The probability of no relationship is less than 1 in 1,000 $(\mathrm{P}<0.001)$ for all combinations in both Tables except for the following: ISA \% and Co-op for all cases, and point count and Co-op for emphysematous lungs $(0.01>\mathbf{P}>0.001)$; Co-op and $\mathrm{ISA}_{c}$ for all lungs, Co-op and ISA \% for emphysematous lungs, and Co-op and ISAc $\%$ for emphysematous lungs $(0.05>\mathrm{P}>0.01)$; Co-op and ISA for all lungs and for emphysematous lungs and Co-op and ISA $_{c}$ for emphysematous lungs $(\mathbf{P}>0.05)$. It should be noted that the Co-op score only is involved in these apparently

${ }^{1}$ A correlation coefficient ( $r$ ) of +1.00 indicates a complete, positive correlation between the two variables considered, and a correlation coefficient of -1.00 indicates a complete, negative correlation. A correlation coefficient of 0.00 indicates no correlation. Thus the further above 0.00 the closer the correlation. diminished probabilities of relationships with various objective measurements. This reflects the small number of cases with Co-op scores since the correlation coefficients for this group are, in fact, no different from the correlation coefficients of the units. Regression equations are not shown. None of those were on a $45^{\circ}$ slope and they can be obtained by request.

From these Tables it is clear that high correlations exist between both the Co-op score and units, and fairly high correlations exist between both the Co-op score and units and $\mathrm{Lm}, \mathrm{Lm}_{\mathrm{c}}$, and ISA $_{5}$. Correlations between ISA and ISAc and Co-op scores are poor, as are their correlations with units. Correction to per cent predicted improves correlations with ISA and ISA $_{c}$, but the values still do not reach those of ISA $_{5}, \mathrm{Lm}$, and $\mathrm{Lm}_{\mathrm{c}}$ with the Co-op score and units. These relationships are not much different when only emphysematous lungs are considered. The point count assessment generally produces lower correlations for $\mathrm{Lm}, \mathrm{Lm}_{\mathrm{c}}$, and $\mathrm{ISA}_{5}$ and correlates relatively poorly with the Co-op score and units. Figures 1 to 4 illustrate some of these relationships, showing the units plotted against ISA, $\mathrm{ISA}_{5}, \mathrm{Lm}$, and the point count against ISA. The mean and range of normal values found in the 29 non-emphysematous lungs are also shown in Figures 1 to 4 . Figure 1 shows that while internal surface area (ISA) generally decreases as the unit assessment of emphysema increases, the relationship is a crude one and the majority of emphysematous lungs have internal surface areas within the wide normal range. Figure 5 illustrates a patient with a unit score of 26 whose ISA was 61 square metres. When alveolar surface area is

T A B L E I RELATIONSHIP BETWEEN CO-OP SCORE, UNITS, POINT COUNT, AND VARIOUS OBJECTIVE NUMBERS IN ALL CASES

\begin{tabular}{|c|c|c|c|c|c|c|c|c|c|c|c|c|c|}
\hline $\mathbf{N}$ & & Units & $\begin{array}{l}\text { Point } \\
\text { Count }\end{array}$ & $\underset{(\mathrm{mm} .)}{\mathbf{L m}}$ & Lm $\%$ & $\begin{array}{c}\mathrm{Lmc} \\
(\mathrm{mm} .)\end{array}$ & $\operatorname{Lm} \%$ & $\begin{array}{l}\text { ISA } \\
\left(\mathrm{m}^{2}\right)\end{array}$ & ISA $\%$ & $\begin{array}{l}\text { ISAc } \\
\left(\mathrm{m} .^{2}\right)\end{array}$ & ISA. $\%$ & $\begin{array}{l}\mathrm{ISA}_{5} \\
\left(\mathrm{~m}^{2}\right)^{2}\end{array}$ & $\operatorname{ISA}_{5} \%$ \\
\hline $\begin{array}{l}22 \\
73 \\
73\end{array}$ & $\begin{array}{l}\text { Co-op score } v \text {. } \\
\text { Units } v \text {. } \\
\text { Point count } v \text {. }\end{array}$ & $\begin{array}{l}0.98 \\
1.00 \\
0.88\end{array}$ & $\begin{array}{l}0.84 \\
0.88 \\
1.00\end{array}$ & $\begin{array}{l}0.91 \\
0.88 \\
0.84\end{array}$ & $\begin{array}{l}0.90 \\
0.87 \\
0.81\end{array}$ & $\begin{array}{l}0.88 \\
0.87 \\
0.82\end{array}$ & $\begin{array}{l}0.88 \\
0.86 \\
0.80\end{array}$ & $\begin{array}{l}-0.40 \\
-0.46 \\
-0.48\end{array}$ & $\begin{array}{l}-0.63 \\
-0.62 \\
-0.64\end{array}$ & $\begin{array}{l}-0.46 \\
-0.53 \\
-0.54\end{array}$ & $\begin{array}{l}-0.76 \\
-0.70 \\
-0.71\end{array}$ & $\begin{array}{l}-0.85 \\
-0.84 \\
-0.82\end{array}$ & $\begin{array}{r}-0.85 \\
-0.83 \\
-0.79\end{array}$ \\
\hline
\end{tabular}

The relationships are expressed as correlation coefficients.

T A B L E I I RELATIONSHIP BETWEEN CO-OP SCORE, UNITS, POINT COUNT, AND VARIOUS OBJECTIVE NUMBERS IN

\begin{tabular}{|c|c|c|c|c|c|c|c|c|c|c|c|c|c|}
\hline $\mathbf{N}$ & & Units & $\begin{array}{l}\text { Point } \\
\text { Count }\end{array}$ & $\underset{(\mathbf{m m} .)}{\mathbf{L m}}$ & $\mathrm{Lm} \%$ & $\underset{(\mathrm{mm} .)}{\mathbf{L} \mathrm{mc}_{\mathrm{c}}}$ & Lmc $\%$ & $\underset{\left(\mathrm{m} .{ }^{2}\right)}{\text { ISA }}$ & ISA $\%$ & $\begin{array}{l}\text { ISAn } \\
\left(\mathrm{m}^{2}{ }^{2}\right)\end{array}$ & ISAc $\%$ & $\underset{\left(\mathrm{m}^{2}\right)}{\mathrm{ISA}_{5}}$ & $\mathrm{ISA}_{5} \%$ \\
\hline $\begin{array}{l}15 \\
44 \\
44\end{array}$ & $\begin{array}{l}\text { Co-op score } v . \\
\text { Units } v \text {. } \\
\text { Point count } v .\end{array}$ & $\begin{array}{l}0.96 \\
1.00 \\
0.74\end{array}$ & $\begin{array}{l}0.71 \\
0.74 \\
1.00\end{array}$ & $\begin{array}{l}0.86 \\
0.84 \\
0.76\end{array}$ & $\begin{array}{l}0.86 \\
0.84 \\
0.72\end{array}$ & $\begin{array}{l}0.85 \\
0.83 \\
0.75\end{array}$ & $\begin{array}{l}0.86 \\
0.83 \\
0.73\end{array}$ & $\begin{array}{l}-0.49 \\
-0.50 \\
-0.53\end{array}$ & $\begin{array}{l}-0.63 \\
-0.61 \\
-0.64\end{array}$ & $\begin{array}{l}-0.43 \\
-0.52 \\
-0.53\end{array}$ & $\begin{array}{l}-0.53 \\
-0.62 \\
-0.64\end{array}$ & $\begin{array}{l}-0.78 \\
-0.82 \\
-0.78\end{array}$ & $\begin{array}{l}-0.81 \\
-0.81 \\
-0.73\end{array}$ \\
\hline
\end{tabular}

The relationships are expressed as correlation coefficients. 


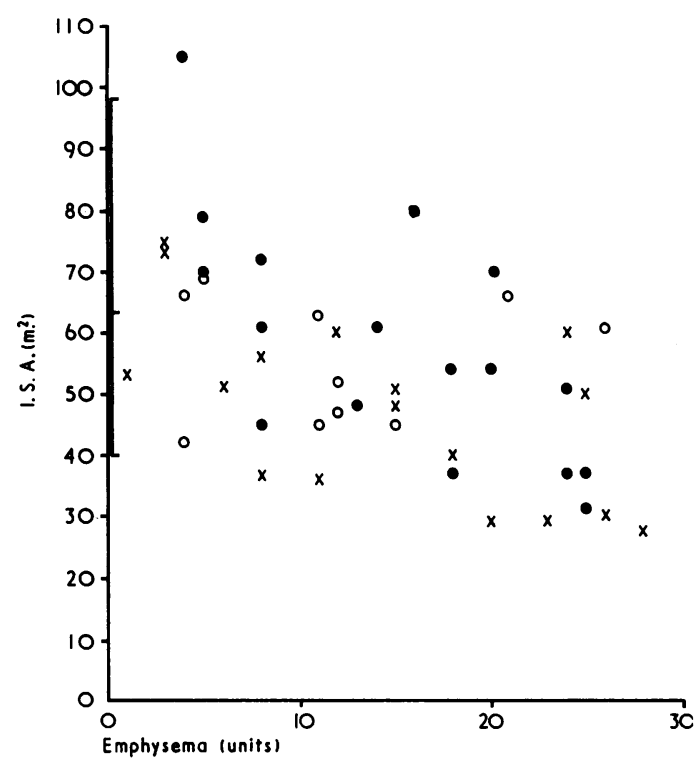

FIG. 1. Internal surface area at a transpulmonary pressure of $25 \mathrm{~cm}$. of formalin (ISA) is compared with a subjective assessment of emphysema (units). The mean (central bar) and range of 29 non-emphysematous lungs are marked at 0 units. pure or dominantly centrilobular emphysema; pure or dominant panlobular (Danacinar) emphysema; $\times$ mixed centrilobular and panlobular (panacinar) or other types of emphysema.



FIG. 3. The average interalveolar distance ( $\mathrm{Lm})$ at a transpulmonary pressure of $25 \mathrm{~cm}$. of formalin is compared to a subjective assessment of emphysema (units). The mean and range of the values in 29 non-emphysematous lungs are marked at 0 units: centrilobular emphysema, pure or dominant; $\bigcirc$ panlobular emphysema, pure or dominant; $\times$ mixed, unclassified, or other emphysema.

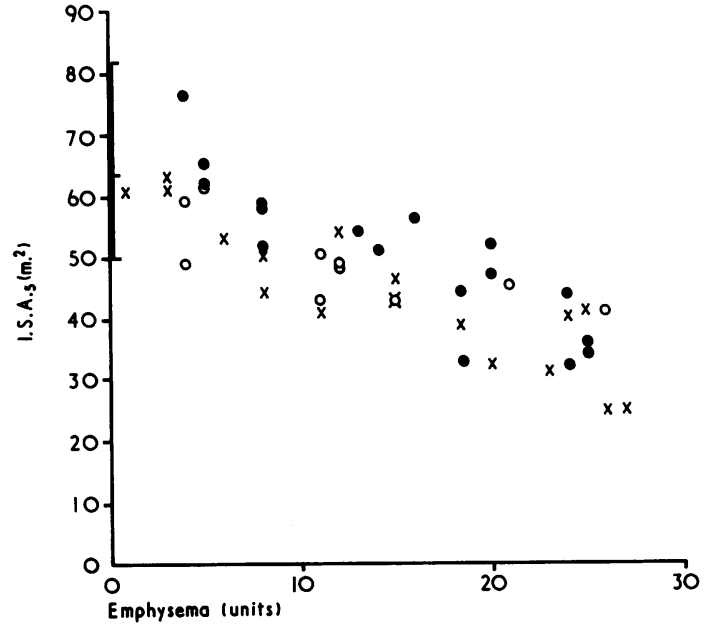

FIG. 2. Internal surface area corrected to an arbitrary lung volume of 5 litres $\left(I S A_{5}\right)$ is compared to a subjective assessment of emphysema (units): - centrilobular emphysema, pure or dominant; $O$ panlobular (panacinar) emphysema, pure or dominant ; $\times$ mixed centrilobular and panlobular emphysema, unclassified emphysema, or other emphysema. The mean (central bar) and range of 29 nonemphysematous lungs are shown at 0 units.

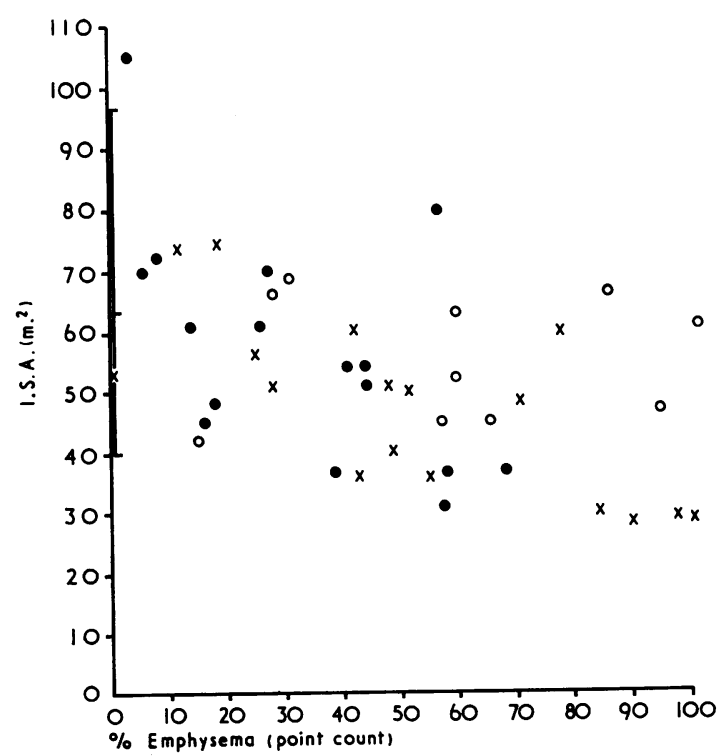

FIG. 4. Internal surface area at a transpulmonary pressure of $25 \mathrm{~cm}$. of formalin (ISA) compared to the percentage of lung involved by emphysema as determined by a stratified random point count $(\%$ emphysema point count $): 0$ centrilobular emphysema, pure or dominant; $\bigcirc$ panlobular emphysema, pure or dominant; $\times$ mixed, unclassified, or other emphysema. 


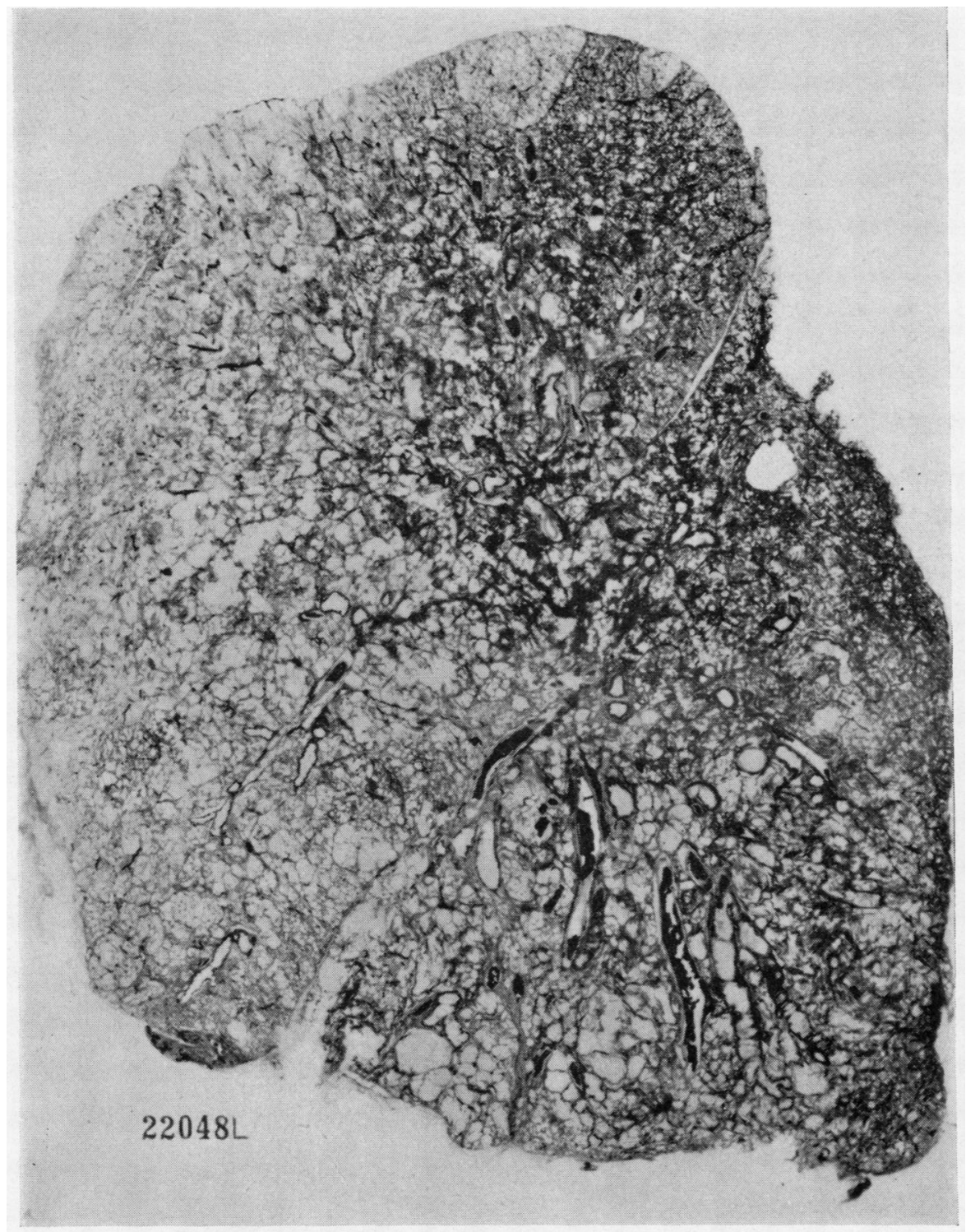

FIG. 5. Despite a subjective assessment of severe panlobular emphysema, alveolar surface areas at both standard transpulmonary pressure $\left(61 \mathrm{m.}^{2}\right)$ and corrected to measured total lung capacity $\left(67 \mathrm{m.}{ }^{2}\right)$ were well within the normal range. Mean linear intercept measurements ( $\mathrm{Lm}$ and $\mathrm{Lm}_{\mathrm{c}}$ ) and ISA are, however, abnormal. Units $26, \mathrm{Lm} 0.534 \mathrm{~mm}$., $L m \% 192, L m_{\mathrm{c}} 0.561 \mathrm{~mm} ., L m_{\mathrm{c}} \%$ 201, ISA $61 \mathrm{m.}{ }^{2}, I S A_{\%}$ 71, ISA $67 m .{ }^{2}, I S A_{\mathrm{c}} \% 87$, $I S A_{6} 41 m .^{2}, I S A_{5} \% 64, \% E 96 \cdot 8$. 




FG. 6. A lung with mild but obvious mixed emphysema (case 31). Despite this internal surface areas are normal. Note the extensive areas of haemorrhagic pneumonitis. Units 3 , Lm 0.303 mm., $L m \%$ 106, $L m_{\mathrm{c}} 0.277$ mm., $L m_{\mathrm{c}} \%$ 98, ISA $74 \mathrm{m.}^{2}, I S A \%$ 108, ISA $62 \mathrm{m.}^{2}$, $I S A_{\mathrm{c}} \%$ 86, ISA $63 \mathrm{~m}_{.}^{2}, I S A_{5} \%$ 102, \% E 19.2, Co-op 0.8 . 


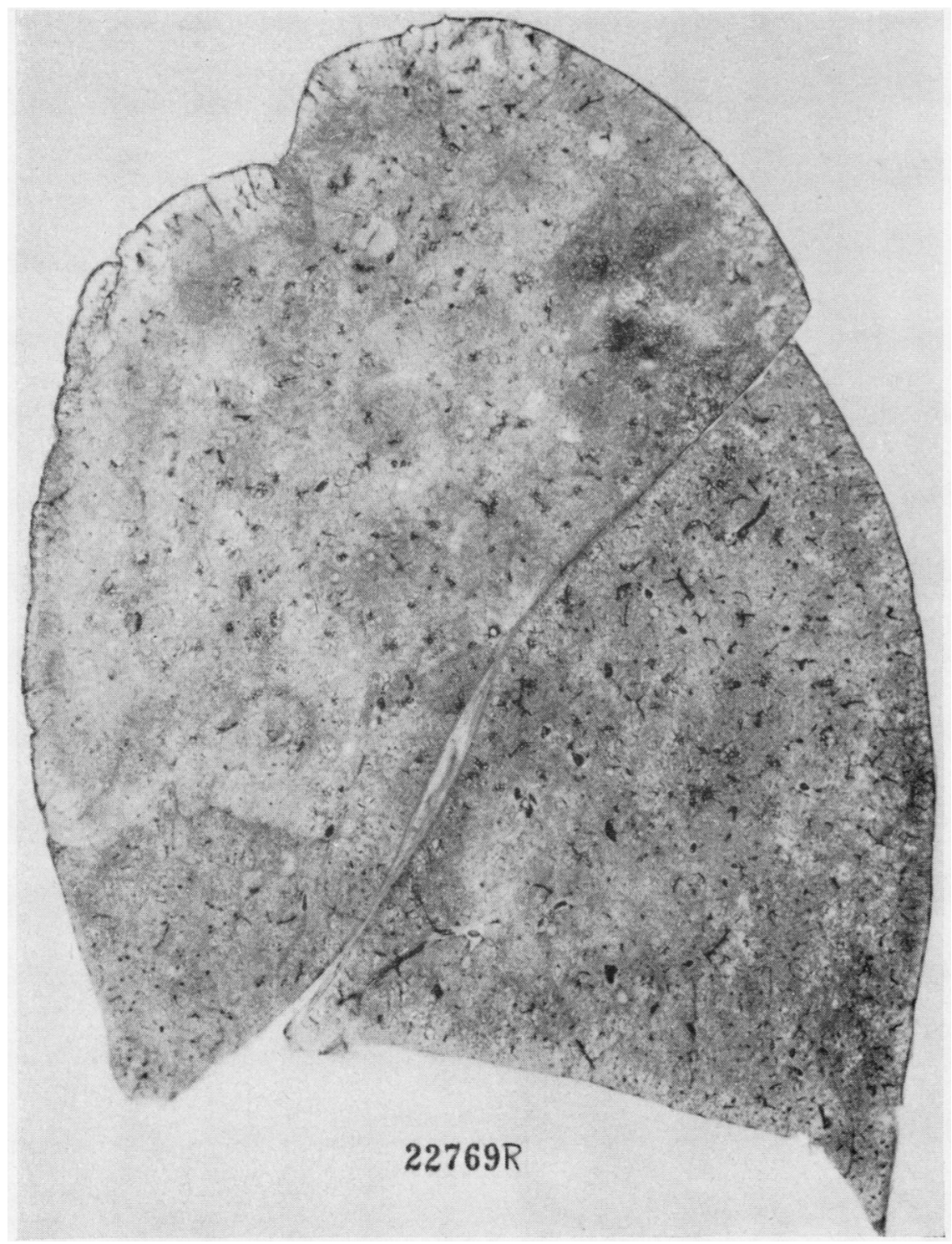

FIG. 7. Another lung with mild but obvious mixed emphysema (case 37) in which surface area measurements were normal. Units $5, \mathrm{Lm} 0.320 \mathrm{~mm}$., Lm\% 116, $\mathrm{Lm}_{\mathrm{c}} \mathbf{0 . 2 9 7} \mathrm{mm}$., $L m_{\mathrm{c}} \% 107, I S A 79 \mathrm{~m}^{2}{ }^{2}, I S A_{\%} \% 124, I S A_{\mathrm{c}} 69 \mathrm{~m}^{2}, I S A_{\mathrm{c}} \% 105, I S A_{5} 62 \mathrm{~m} .^{2}, I S A_{5} \% 97, \% E 17 \cdot 1$, Co-op 0.9. 


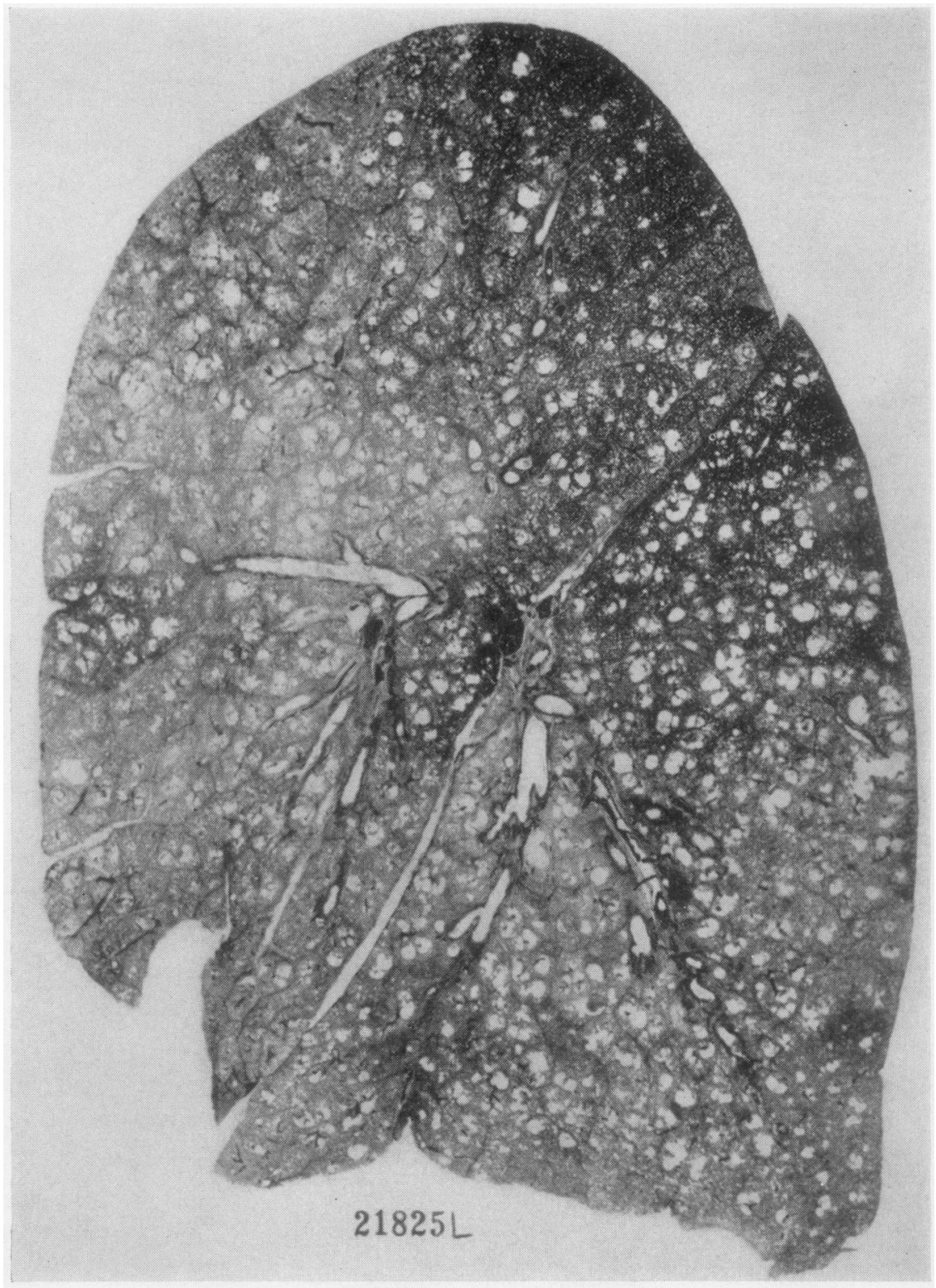

FIG. 8. A lung with widespread centrilobular emphysema, whose internal surface area was

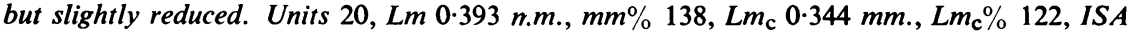
$70 m .^{2}, I S A_{\%} \% 107, I S A_{\mathrm{c}} 54 m .^{2}, I S A_{\mathrm{c}} \% 81, I S A_{5} 52 m^{2}, I S A_{5} \% 83, \% E 27 \cdot 8$, Co-op 2.4. 




FIG. 9. Another example of dominantly centrilobular emphysema, but in which surface area

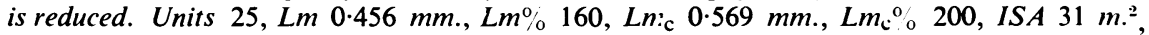
$I S A^{\%} \% 41, I S A_{\mathrm{c}} 48 m .^{2}, I S A_{\mathrm{c}} \% 61, I S A_{5} 36 m .^{2}, I S A_{5} \% 58, \% E 57 \cdot 5$. 
expressed at an arbitrary lung volume of 5 litres, the range in non-emphysematous lungs is smaller (Fig. 2) and a little over half the patients with emphysema have abnormal values. However, only one patient with 'mild' emphysema ( 1 to 5 units) falls outside the range of normal, and the rest are very close to the mean value for non-emphysematous lungs except for one with a high value. Two examples of this group are shown in Figures 6 and 7. Figure 2 also shows that many of the patients with emphysema considered to be purely or dominantly centrilobular in type had relative. preservation of surface area. Figure 8 illustrates one classic such example. That surface area is not always preserved in centrilobular emphysema is shown in Figure 9. Figure 3 shows that the mean cord at $25 \mathrm{~cm}$. of formalin is generally increased in emphysema. Similar trends to ISA $_{5}$ are apparent - the lungs with 'mild' emphysema have $\mathrm{Lm}$ values within the normal range and $\mathbf{L m}$ is often, but not always, preserved in centrilobular emphysema. Figure 4 illustrates the fact that there is only a crude correlation between the point count assessment of emphysema and ISA.

\section{DISCUSSION}

Alveolar surface area has been measured in relatively few lungs with emphysema. Dunnill (1965) found that four of five pairs of lungs with centrilobular emphysema had values of 66 to 69 sq. m., close to his assumed normal of $70 \mathrm{sq}$. $\mathrm{m}$. The remaining patient had the highest proportion of the lung involved by centrilobular emphysema $(30.5 \%)$ and had a surface area of 40 sq. m., but the patient was an 'extremely small woman'. By contrast, he found that all but one patient with panlobular (panacinar) emphysema had internal surface areas thought to be abnormally small. Duguid et al. (1964) made measurements on one lung only in most of their cases. Assumptions must be made in comparing their data to those of others. If the assumption is made that the right lung contributes $53 \%$ of the total alveolar surface area (which was the mean value of non-emphysematous lungs in this series), their range of surface area was 57 to 79 sq. m. in five non-emphysematous subjects whose data they considered adequate. Eleven subjects with emphysema had surface areas of 28 to 62 sq. m., three of them falling within the normal range. They also decided to express internal surface area at an arbitrary lung volume, choosing the volume of $\mathbf{3 . 0}$ litres for a single lung. Internal surface area at this volume will be referred to subsequently as ISA $_{3}$. They made the same assumptions as were made here-namely, that the internal surface area varies to the two-thirds $\overline{\bar{s}}$ power of the change in volume. When this was $\mathbb{Q}$ done, surface areas of single lungs varied between 38 and 44 sq. $\mathrm{m}$. in non-emphysematous subjects, and all examples of emphysema had internal. surface areas of less than 30 sq. m. The majority, $\overrightarrow{\vec{H}}$ if not all, of their patients were certified pneumo- $\omega$ coniotics and the type of emphysema was not classified. Three lungs with only mild emphysema are illustrated in their paper $(289 / 59,55 / 59$, and? $185 / 59$ ) in which internal surface areas at $a_{0}^{\circ}$ standard lung volume were reduced.

More recently, Hicken, Brewer, and Heatho (1966) measured the internal surface area of seven ${ }_{-}$ pairs of emphysematous lungs and reported one $z$ case in which internal surface area fell within the? range of 48 to 83 sq. $m$. found in three non- $\frac{\Phi}{3}$ emphysematous subjects. The remaining six casesర్ల had internal surface areas below the normal range. They also expressed internal surface area at aco standard lung volume of 6 litres, making the same. corrections as Duguid. The lowest value found in non-emphysematous lungs was then 61.5 sq. m. and the highest in emphysematous lungs was 55 sq. $m$. The emphysematous lungs were notg illustrated, but the latter example appears to beD from a 38-year-old patient with about $15 \%$ of the lung volume involved by centrilobularo emphysema (Hicken, Heath, and Brewer, 1966).

If the loss of internal surface area in emphy sema is to be assessed, knowledge of normal internal surface area is essential. A wide variation $\overrightarrow{0}$ of internal surface area is present in non-ض emphysematous lungs inflated to standard pressure (Thurlbeck, 1967a), but this range is smaller when alveolar surface area is corrected to an arbitraryo standard volume, as is shown in Figures 1 and 2.2 Figure 10 illustrates all published internal surface areas with sufficient data to correct to a standard lung volume of 5 litres. The cases of Duguido et al. (1964) were corrected to ISA $A_{5}$, assuming tha? the right lung contributed 2.65 litres $(53 \%$ of 20 TLV of 5 litres) and the left lung contributed 2.35 litres of the arbitrary 5-litre volume. If, fon example, a left lung was expressed at ISA by $_{0}^{\omega}$ them, this would be recalculated to ISA $_{5}$ for both lungs as follows:

$$
\mathrm{ISA}_{5}=\mathrm{ISA}_{3}\left(\frac{2 \cdot 35}{3}\right)^{\frac{2}{3}} \times \frac{5}{2 \cdot 35}
$$

The calculation for the right lung would be :

$$
\mathrm{ISA}_{5}=\mathrm{ISA}_{3}\left(\frac{2 \cdot 65}{3}\right)^{\frac{2}{3}} \times \frac{5}{2 \cdot 65}
$$




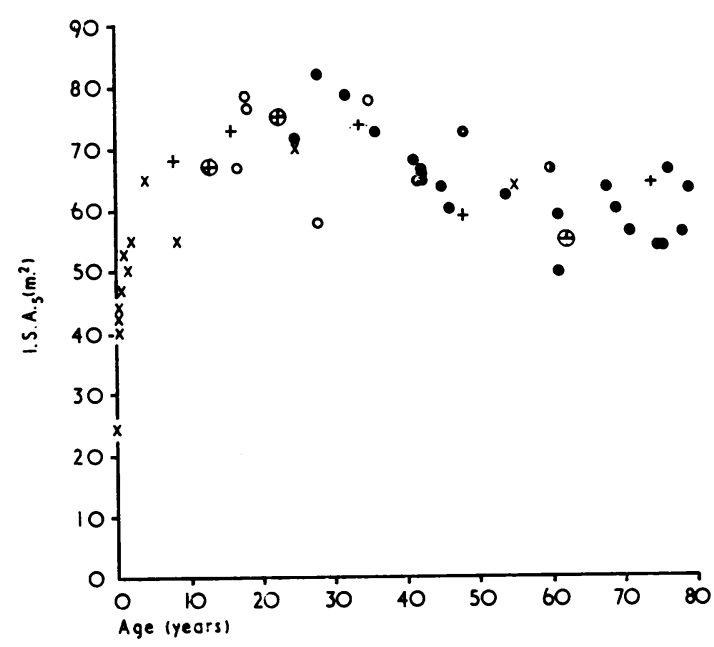

FIG. 10. The relationship between age and surface area expressed at a standard lung volume of 5 litres $\left(I S A_{5}\right)$ : $\times$ from Dunnill (1962b, 1964); + from Weibel (1963); from Duguid et al. (1964); from Thurlbeck (1967a); $\oplus$ from Hicken et al. (1966).

Figure 10 shows that the reported results are similar. There is a rise in internal surface area from birth until maximum lung volume is reached at about age 20 years. Thereafter there is a loss of internal surface area of about 2.7 sq. m. by decade (Thurlbeck, 1967a), although the exact point of inflection is still uncertain. Comparison of the surface areas of patients with emphysema arbitrarily termed 'mild' (1 to 5 units) shows that these patients had ISA $_{5}$ values which are not distinguishable from those of non-emphysematous patients. Of the nine patients in this group, one had abnormally low values, but the other eight are close to normal, the lowest having an ISA $_{5}$ of $97 \%$ of predicted. The group as a whole had normal mean internal surface areas no matter how they were expressed. Since the assessment of emphysema as 'mild' is clearly a subjective one, it is necessary to justify this group as having emphysema and that it is of a mild grade. The presence of emphysema is shown in two of the cases in Figs 6 and 7. Further, five of the cases in this group were examined by eight other pathologists, expert in emphysema, and these lungs were considered as having an average assessment (Co-op score) higher than those considered by me to have no emphysema (Table III). They also had a lower Co-op score than those lungs considered to have moderate emphysema. This group of cases is an important one, since it forms about half the cases of emphysema seen in a random necropsy population in a general hospital (Thurlbeck, 1963b). Thus, there is little doubt that obvious, but not severe, emphysema frequently produces no change in internal surface area. One of the patients in the 'mild' emphysema group had low internal surface area values. Reexamination of the lung and the data showed no errors. The patient did, however, have severe terminal pneumonia which may be responsible for the reduction in surface area, but pneumonia was found in other cases with appropriate surface area measurements (Fig. 6). Other possible explanations exist. Determination of internal surface area is based on statistical sampling and one should anticipate finding anomalous values on the basis of normal statistical distribution. There are a number of difficulties in making internal surface area measurements and there is a potential source of error (Thurlbeck, 1967b), and this may have been the cause.

On the other hand, patients arbitrarily considered to have 'severe' emphysema (with 16 or more units of emphysema) generally had low values for internal surface area, the lowest being 28 sq. m., which was $37 \%$ of predicted when expressed at a standard lung volume of 5 litres. All except two patients had ISA $_{5}$ values of less than $80 \%$ of predicted, and the mean value of the group as a whole was $62 \%$ of predicted. The two patients with ISA $_{5}$ of $80 \%$ or more of predicted are of interest. One had widespread centrilobular emphysema and ISA $_{5}$ was $83 \%$ of

T A B L E I I I

MEAN VALUES OF VARIOUS MEASUREMENTS IN THE CASES GROUPED ACCORDING TO SEVERITY OF EMPHYSEMA AS ASSESSED BY A SUBJECTIVE VISUAL GRADING

\begin{tabular}{|c|c|c|c|c|c|c|c|c|c|c|c|c|c|c|c|c|}
\hline \multicolumn{3}{|c|}{ Emphysema Group } & \multirow{2}{*}{$\begin{array}{l}\mathrm{N} \\
29 \\
10 \\
16 \\
18\end{array}$} & \multirow{2}{*}{\begin{tabular}{|c|}
$\begin{array}{c}\text { Co-op } \\
\text { Score }\end{array}$ \\
0.2 \\
0.8 \\
1.6 \\
2.8
\end{tabular}} & \multirow{2}{*}{$\begin{array}{c}\text { Units } \\
0 \\
3 \cdot 8 \\
11 \cdot 0 \\
22 \cdot 2\end{array}$} & \multirow{2}{*}{$\begin{array}{c}\begin{array}{c}\text { Point } \\
\text { Count } \\
(\%)\end{array} \\
0 \\
14.8 \\
43.0 \\
64.6\end{array}$} & \multirow{2}{*}{$\begin{array}{c}\begin{array}{c}\text { Lm } \\
(\mathrm{mm} .)\end{array} \\
0.279 \\
0.304 \\
0.369 \\
0.517\end{array}$} & \multirow{2}{*}{$\begin{array}{c}\text { Lm \% } \\
102 \\
106 \\
130 \\
182\end{array}$} & \multirow{2}{*}{$\begin{array}{c}\begin{array}{c}\text { Lmc } \\
(\mathrm{mm} .)\end{array} \\
0.283 \\
0.288 \\
0.375 \\
0.513\end{array}$} & \multirow{2}{*}{$\begin{array}{c}\text { Lme \% } \\
102 \\
101 \\
133 \\
182\end{array}$} & \multirow{2}{*}{$\begin{array}{c}\begin{array}{c}\text { ISA } \\
\left(\mathrm{m} . .^{2}\right)\end{array} \\
63 \\
70 \\
52 \\
47\end{array}$} & \multirow{2}{*}{$\begin{array}{c}\text { ISA \% } \\
98 \\
107 \\
76 \\
67\end{array}$} & \multirow{2}{*}{$\begin{array}{c}\begin{array}{l}\text { ISAc } \\
\left(\mathrm{m}^{2}\right)\end{array} \\
65 \\
63 \\
54 \\
45\end{array}$} & \multirow{2}{*}{$\begin{array}{c}\text { ISAc \% } \\
98 \\
94 \\
76 \\
64\end{array}$} & \multirow{2}{*}{$\begin{array}{c}\begin{array}{l}\mathrm{ISA}_{5} \\
\left(\mathrm{~m} .^{2}\right)\end{array} \\
64 \\
62 \\
49 \\
39\end{array}$} & \multirow{2}{*}{$\begin{array}{r}\text { ISA }_{5} \% \\
98 \\
101 \\
79 \\
62\end{array}$} \\
\hline $\begin{array}{l}0 \text { (none) } \\
\text { Mild ... } \\
\text { Moderate } \\
\text { Severe.. }\end{array}$ & $\begin{array}{l}\ldots \\
\ldots \\
\ldots\end{array}$ & $\begin{array}{l}\cdots \\
\cdots \\
\cdots\end{array}$ & & & & & & & & & & & & & & \\
\hline
\end{tabular}

The numbers of cases with Co-op scores are as follows: No emphysema, 7; 'mild' emphysema, 5; 'moderate' emphysema, 5 ; 'severe' emphysema, 5 . 
predicted (Fig. 8), and this is in keeping with Dunnill's concept of preservation of internal surface area in centrilobular emphysema. The other patient was more surprising: there was widespread mild lower zonal panlobular (panacinar) emphysema and upper zonal bullous emphysema of the lung, interpreted as centrilobular emphysema. Despite this the patient had a surface area within normal limits. Once again, the most reasonable explanation for this is probably statistical sampling limitations or unavoidable errors in technique.

In the intervening grade of emphysema ('moderate'-6 to 15 units) surface areas intermediate between those in 'mild' emphysema and 'severe' emphysema were found. The various values in the various groups are shown in Table III. Similarly, the five patients with 'moderate' emphysema, submitted to the eight expert pathologists, received Co-op scores intermediate between those given to lungs thought to have 'mild' emphysema and those with 'severe' emphysema. There were four patients in the moderate group who had internal surface areas of $85 \%$ or more predicted. Three of these had almost pure centrilobular emphysema and one had a mixture of types of emphysema. It follows then that the majority of lungs which had less loss of internal surface area than their subjective assessment of emphysema indicated were examples of centrilobular emphysema. The assessment of emphysema in these cases may have been inappropriate. However, in general terms the lungs were scored appropriately by the eight pathologists, and the patients had disturbances of pulmonary function appropriate for this category of emphysema. Thus there is a category of centrilobular emphysema in which surface area remains relatively intact. This is not always the case even in those patients with moderate emphysema. One case, considered to have moderate centrilobular emphysema by myself and most of the panel, had a significantly reduced surface area. In this case there was probably destruction of the acinus peripheral to the centrilobular emphysematous spaces which was not appreciated at the time because of the attention paid to the striking centrilobular lesions. Were the centrilobular emphysematous spaces not there, then parenchymal abnormalities would be more readily recognized as such.

It is difficult to assess the value of objective measurements of quantitating emphysema, since there are no absolute criteria with which they can be compared. While these measurements are usually obviously abnormal in severely emphysematous lungs, their value as a measurement should be compared to another agreed ranking or measurement. There is a wide variation in the interpretation of the presence or absence of emphysema or the severity of emphysema by expert observers (Stuart-Harris, 1965). It is thus presumptuous to compare the objective measurements made here to a single observer's subjective assessment of emphysema. However, a number of categorical statements can be made:

(a) The objective measurements parallel the subjective measurements of emphysema, either by point count, units, or Co-op score. The relationships are variable-internal surface area measurements decrease and mean linear intercept measurements increase. ISA and ISA $_{c}$ generally show a poorer correlation than $\mathrm{ISA}_{5}, \mathrm{Lm}$, and $\mathrm{Lmc}_{c}$ with either point count, units, or Co-op score. Expressing ISA ${ }_{5}, \mathrm{Lm}$, or $\mathbf{L m}_{\mathrm{c}}$ as a percentage of predicted did not result in higher correlation coefficients. Similarly, correcting Lm and ISA to measured TLC $\left(\mathrm{Lm}_{\mathrm{c}}\right.$, ISA $)$ did not particularly improve the relationship over that of Lm or ISA.

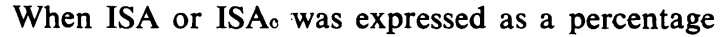
of predicted, the correlations with all of the subjective measurements improved, but none the less did not approach $\mathrm{Lm}$, or $\mathrm{Lm}_{\mathrm{c}}$ or $\mathrm{ISA}_{5}$.

(b) It was previously shown that surface area measurements could be normal in the presence of unequivocal emphysema. The same is true of mean linear intercept measurements. However, Lm may have an advantage over internal surface area measurements and $\mathrm{Lm}_{\mathrm{c}}$ in recognizing mild grades of emphysema. While Lm measurements of mildly emphysematous lungs fell within the range found in non-emphysematous lungs, the mean $\mathrm{Lm}$ in mild emphysema was different from the mean normal $\mathrm{Lm}$ at conventional levels of significance $(0.02<\mathrm{P}<0.05$; student $t)$. It thus may be useful in dealing with groups but not with individual cases.

(c) The Co-op score represents the average opinion of a group of pathologists expert in emphysema. It is unlikely to represent the absolute truth, but it is the best subjective measurement with which to compare the objective measurements. ISA, $\mathrm{Lm}$, and $\mathrm{Lm}_{\mathrm{c}}$ are the objective measurements which correlate best with the Co-op score. $\mathrm{Lm}_{\mathrm{c}}$ is derived from $\mathrm{Lm}$, involves assumptions, and does not improve the correlation. There seems no valid reason, therefore, for using $\mathrm{Lm}_{\mathrm{c}}$ further. $I_{S A_{5}}$ is similarly derived from $\mathbf{L m}$ (via TLV and an assumption) and also does not show an advantage in terms of correlation. However, it 
does overcome the vexed problem of the degree of inflation of excised lungs outside the thorax (Thurlbeck, 1967b) and the assumption is probably a valid one. Whether or not it should be used further depends on the extra effort involvedmeasuring TLV and non-parenchyma and calculating ISA $_{5}$. I believe it is, for the reasons that the difficulties with inflation are overcome and the resultant figure is an easy one to grasp.

Expressing $\mathrm{Lm}, \mathrm{Lm}_{c}$, and $\mathrm{ISA}_{5}$ as a percentage of predicted added nothing to the correlations, largely because the range of normals is small and because prediction data are derived from age and the age range of the patients studied was small. ISA and ISA $_{c}$ correlated poorly with the Co-op score. This occurs because the normal range of alveolar surface area is so large. When expressed as a percentage of predicted, correlations improved because the prediction figures are body length dependent and the body length was quite variable in the patients. The fact that ISA $_{5}$ was superior to even the corrected figures may indicate the difficulties in obtaining correct lung volumes post mortem which were obviated by the use of a standard volume.

(d) The objective measurements followed the same trend they had done with the Co-op score when they were compared to either units or the point count. Generally speaking, the point count correlated less well with the objective measurements than did the Co-op score or units, and the point count correlated less well with the Co-op score than did the units. The point count has serious disadvantages which have been enumerated elsewhere (Thurlbeck, 1967b). It is a subjective method and does not make allowance for the severity of emphysema.

(e) The units correlated best with the Co-op score and also distinguished 'mild' grades of emphysema which the objective measurements failed to do. This experience with a subjective visual grading system is not unique. Seven of the eight expert pathologists produced similarly high correlations with the Co-op score, using their own subjective visual grading systems.

It thus seems clear that absolute alveolar surface area-either at a standard inflating pressure or corrected to TLC-is a poor measurement of emphysema, although generally reduced in step with the severity of emphysema. Lm and ISA appear to be better measurements but do not adequately recognize mild grades of emphysema obvious to the naked eye. A subjective visual grading system (units) recognizes these cases of emphysema and also correlates very well with the average assessment of emphysema made by a group of experts. However, the unit assessment, or any other similar subjective system, is peculiar to the observer and liable to be affected by the opinions and emotions of that observer. Also, the actual numbers generated by different systems are likely to be different from one observer and his system to the next. Further, the subjective systems are private ones, i.e., the only person who can use a particular grading system is the person who devised it, and the results obtained from this system may be different when used by different observers. These objections would not apply to objective measurements. We thus have to weigh a relatively insensitive objective system with a sensitive subjective one.

In view of these differences, it is pertinent to consider the purposes of measurement, since subjective and objective measurements may have separate functions. For example, large-scale surveys of emphysema in necropsies ideally require a measurement which is quick and simple but the measurement must recognize mild grades of emphysema which form a major portion of incidentally found emphysema. Clearly, the objective measurements described here do not fulfil these criteria and should not be pursued further in this regard. A more rational approach would be to develop a standardized subjective visual grading system for this purpose. Contrarily, the extra time may be well spent when relatively few cases are to be studied, such as correlative studies of structure and function. This is particularly true since there is at present no agreed subjective visual grading system and the same experience may be described differently because different subjective methods are used. Interpretation of emphysema in these circumstances is critical, and objective measurements would be of value so that observers can interpret the data of others. Objective measurements are based on sampling, thus extra sampling will improve their sensitivity and the extra effort may be worth while in these groups of cases. However, many lungs from which one may wish to make measurements-particularly emphysematous lungs-may be far from ideal, being pneumonic, infarcted, or haemorrhagic, and this may mitigate the gains made by extra sampling.

The fact that the mean $\mathrm{Lm}$ was increased in the group of 'mild' emphysema whereas the mean ISA $_{5}$ was not altered in this group raises interesting speculations. Since internal surface area is derived from the dividend of lung volume by mean linear intercept, this suggests that lung 
volume was increased pari passu with the increase in mean linear intercept. Since a standard transpulmonary pressure was used to inflate the lungs this suggests that elastic recoil was lost in the patients with 'mild' emphysema. It is difficult to ascribe this putative loss of elastic recoil to the slight degree of emphysema, although conventional wisdom dictates that the changes in elastic recoil accompany or succeed the emphysematous lesions; might they not precede them ? Loss of elastic recoil in aged, non-emphysematous lungs was postulated from morphological data (Thurlbeck, 1967a) and these lungs are similar in some respects to those of patients described here with 'mild' emphysema. Aged non-emphysematous lungs and lungs 'with 'mild' emphysema have similar abnormalities of function and objective measurements when compared to young nonemphysematous lungs. The lungs of patients with 'mild' emphysema differ from the aged nonemphysematous lungs by the presence of clear-cut destructive enlargement of respiratory tissue. Perhaps it may be possible for lungs from patients of the same age to differ in elastic properties and yet not in the presence of morphological emphysema. Might this not be the predecessor to morphological emphysema ? Although interesting, these speculations cannot be profitably pursued at the present time.

This work was supported by the Medical Research Council of Canada and the Canadian Tuberculosis
Association. I wish to thank Drs. A. E. Anderson, D. Greenberg, M. Janis, R. Mitchell, P. Pratt, G. $\overline{\bar{n}}$ Restrepo, S. Ryan, and T. Vincent for interpretations $\vec{\Phi}$ used for the 'Co-op score'.

\section{REFERENCES}

Ciba Guest Symposium (1959). Terminology, definitions, and classification of chronic pulmonary emphysema and related con- $\omega$ ditions. Thorax, 14, 286.

Duguid, J. B., Hulse, E. V., Richardson, M. W., and Young, A. E. (1953). A method of calculating the respiratory surface area of the lung. J. Physiol. (Lond.), 121, 8P.

- Young, A., Cauna, D., and Lambert, M. W. (1964). The ? internal surface area of the lung in emphysema. J. Path. Bact., O $88,405$.

Dunnill, M. S. (1962a). Quantitative methods in the study of pulmonary pathology. Thorax, 17, 320.

- (1962b). Postnatal growth of the lung. Ibid., 17, 329.

(1964). Evaluation of a simple method of sampling the lung for quantitative histological analysis. Ibid., 19, 443.

- (1965). Quantitative observations on the anatomy of chronic $O$ non-specific lung disease. Med. thorac. (Basel), 22, 261.

Heard, B. E. (1958). A pathological study of emphysema of the lungs with chronic bronchitis. Thorax, 13, 136.

Hicken, P., Brewer, D., and Heath, D. (1966). The relation between $\mathbb{D}$ the weight of the right ventricle of the heart and the internal surface area and number of alveoli in the human lung in emphysema. J. Path. Bact., $92,529$.

- Heath, D., and Brewer, D. (1966). The relation between the weight of the right ventricle and the percentage of abnormal air space in the lung in emphysema. Ibid., 92, 519.

Stuarr-Harris, C. H. (1965). The pathogenesis of chronic bronchitis and emphysema. Scot. med. J., 10, 93.

Thurlbeck, W. M. (1963a). A clinico-pathological study of emphysema in an American hospital. Thorax, 18, 59.

- (1963b). The incidence of pulmonary emphysema, with observations of the relative incidence and spatial distribution of various types of emphysema. Amer. Rev. resp. Dis., 87, 206.

- (1967a). The internal surface area of non-emphysematous lungs. Ibid., 95, 765 .

(1967b). Measurement of pulmonary emphysema. Ibid., 95, 752.

Weibel, E. R. (1963). Morphometry of the Human Lung. Springer, Berlin. 